\title{
Polycyclic aromatic hydrocarbons in Chinese surface soil: occurrence and distribution
}

\author{
Wan-Li Ma $\cdot$ Li-Yan Liu $\cdot$ Chong-Guo Tian $\cdot$ Hong Qi • \\ Hong-Liang Jia $\cdot$ Wei-Wei Song $\cdot$ Yi-Fan Li
}

Received: 2 July 2014 / Accepted: 22 September 2014 / Published online: 4 October 2014

(C) Springer-Verlag Berlin Heidelberg 2014

\begin{abstract}
In this study, 16 polycyclic aromatic hydrocarbons (PAHs) were analyzed in 157 concurrently collected soil samples in 2005 over China. Higher concentration of $\sum_{16} \mathrm{PAHs}$ was found in urban soil, followed by rural and background soil. The results indicated that PAHs in Chinese surface soil showed a primary distribution pattern, which was confirmed by the positive correlation with emission inventory. Based on the results of literature over the past 10 years (20042013) in China, the spatial distribution of PAHs in urban and rural soil was established. An obvious geographical distribution with PAH concentration was found, as higher in Eastern China and lower in Middle and Western China. Furthermore, PAH pollution in Chinese riverbank soil was summarized and showed higher levels, indicating their potential sources from polluted rivers. According to our knowledge, this is the first time to comprehensively study the PAH pollution status in Chinese surface soil on the national scale based on monitoring results.
\end{abstract}

Responsible editor: Zhihong Xu

Electronic supplementary material The online version of this article (doi:10.1007/s11356-014-3648-3) contains supplementary material, which is available to authorized users.

W.-L. Ma $\cdot$ L.-Y. Liu $\cdot$ H. Qi $・$ W.-W. Song $・$ Y.-F. Li $(\bowtie)$ International Joint Research Center for Persistent Toxic Substances (IJRC-PTS), State Key Laboratory of Urban Water Resource and Environment, School of Municipal and Environmental Engineering, Harbin Institute of Technology, 202 Haihe Road, Nangang District, Harbin 150090, Heilongjiang, China

e-mail: ijrc_pts_na@yahoo.com

C.-G. Tian

Key Laboratory of Coastal Zone Environmental Processes, Yantai Institute of Coastal Zone Research (YIC), Chinese Academy of Sciences (CAS); Shandong Provincial Key Laboratory of Coastal Zone Environmental Processes, YICCAS, Yantai 264003, China

H.-L. Jia

IJRC-PTS, Dalian Maritime University, Dalian 116026, China
Keywords PAHs · Surface soil · Occurrence · Geographical distribution $\cdot$ Monitoring $\cdot$ Over China

\section{Introduction}

Polycyclic aromatic hydrocarbons (PAHs) are a large group of organic compounds, which include carbon and hydrogen with a fused ring structure containing at least two benzene rings (Ravindra et al. 2008). PAHs have been attracting a great attention due to their mutagenic and carcinogenic toxicity and widespread occurrence in environment (Zheng et al. 2014). Generally, 16 PAHs are regarded as priority pollutants by both the US Environmental Protection Agency (US EPA) and the European Community (Dimashki et al. 2001). Some of them were also listed as priority pollutants by the Chinese Government in the Environmental Quality Standard for Surface Water and the Ambient Air Quality Standard. Although PAHs have some natural sources, such as forest fires and volcanic eruptions, they are mainly originated from anthropogenic activities (Mastral and Callen 2000; Morillo et al. 2007; Srogi 2007). Once releasing into air, they distribute between gas and particle phases and drop to surface soil through wet and dry depositions (Morillo et al. 2007). Soil is an important long-term repository for organic compounds, which can be used as an indicator for the environmental pollution of PAHs (Srogi 2007). Therefore, PAH pollutions in surface soil have received enhanced attention in recent years (Wilcke 2007). Monitoring program was considered as an important tool for the study of PAH pollution in soil (Wilcke 2000), which have been successfully conducted to study the environmental fate of PAHs in soil on national, continental, and even global scale (Bucheli et al. 2004; Heywood et al. 2006; Nam et al. 2003; Nam et al. 2008). For example, 201 rural surface soil samples were collected to identify the factors influencing the national distribution of PAHs across the Great Britain (Heywood et al. 
2006), and 108 soil samples were collected to study the environmental fate of PAHs in global background soil (Nam et al. 2009).

In the past several decades, PAH pollution has become a serious environmental problem in China due to the rapid urbanization and economic development. For example, almost $22 \%$ of the global emission of PAHs was originated from China in 2004 (Zhang and Tao 2009). High levels of PAH contamination were reported in large cities (e.g., Beijing, Tianjin, and Shanghai) and social-economical developed regions in China (e.g., the Pearl River Delta) (Cai et al. 2007; Jiang et al. 2009; Ma et al. 2005; Wang et al. 2010). PAHs were even detected in surface soil in high-mountain regions (e.g., Mt. Qomolangma, 8,844.3 m a.s.l) and vast remote areas (e.g., the Qinghai-Tibetan Plateau), which indicated the national wide pollution of PAHs in China (Tao et al. 2011; Wang et al. 2007). In addition to local and national influence across China, PAH pollution can also influence the neighbor countries and regions through long-range atmospheric transport (Inomata et al. 2012; Lang et al. 2008; Primbs et al. 2008).

In China, many studies were conducted to investigate the pollution levels of PAHs in surface soil, and the scientific interest is still continuously increasing. However, most of the studies only focused on large cities, small areas, and local regions, and there is still no systematic nationwide database publicly available. So, the first objective of this study is to investigate the pollution status of PAHs and the corresponding influencing factors on the national scale by concurrently collected 157 surface soil samples over China in 2005. Then, the national pattern of PAH pollution (occurrence and concentration) was reviewed with results of the corresponding studies in the past 10 years (2004-2013). Therefore, the second objective is to establish the geographical distribution pattern of PAH pollution for different types of soils (urban, rural, and riverbank soils). The efforts of this study would provide a scientific basis for assessing human exposure and establishing policies to reduce PAH pollution in China.

\section{Methodology}

\section{Sampling}

A total of 157 surface soils $(0-20 \mathrm{~cm})$ were collected in 2005 across China, and the spatial distribution of sampling sites is presented in Fig. 1. Among the 157 soil samples, 9 are background soils, 120 are rural soils, and 28 are urban soils. The background sites are chosen to ascertain that these sites are far away any human activities, at least $10 \mathrm{~km}$ far away from any populated areas, such as cities, towns, and villages. Furthermore, all the nine sites were chosen to be representative of background area, including original grassland and forestland. All rural samples are from croplands in rural areas, and the urban samples are from woodland, grassland, roadside soil, and vegetable garden soil in urban regions. During sampling, large rocks, plant roots, and other residues were picked out from the soil samples. All the soil samples were stored frozen $\left(-20{ }^{\circ} \mathrm{C}\right)$ until required for treatment in the laboratory of the International Joint Research Center for Persistent Toxic Substances.
Fig. 1 Distribution of sampling sites of surface soil in China in 2005

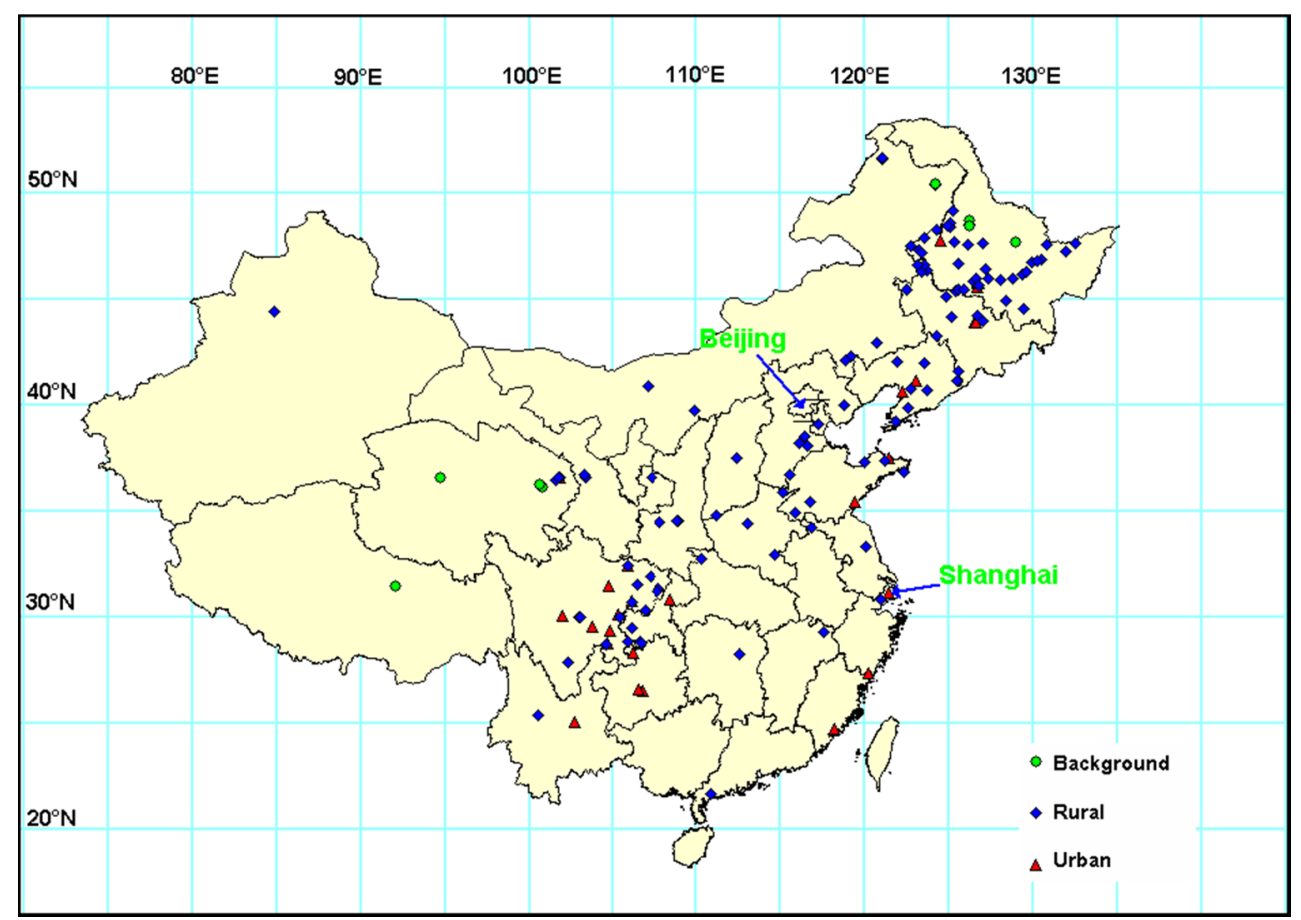


Sample treatment and analysis

Details on soil treatment procedures can be found in our previous studies (Ma et al. 2009; Ren et al. 2007). Only brief description was provided here. Before extraction, all the soil samples were defrosted. Then, the soil samples were grinded, and during the same time small rocks, plant roots and other residues were picked out. After homogenization, soil sample was divided into two parts, one for moisture and soil organic carbon (SOC) fractions determination and the other for PAH analysis. For moisture and SOC fraction determination, soil sample was air-dried. The concentration of SOC was directly determined by TOC-VCPN technique (Shimadzu Co., Japan). For PAH analysis, 10-g soil sample (without air-drying) was accurately measured into a pre-cleaned paper bag. After being spiked with labeled recovery standards (surrogates), containing naphthalene-D8, fluorene-D10, pyrene-D10, and perylene-D12 (Supelco Co., USA), soil samples were Soxhlet extracted for $24 \mathrm{~h}$ with a $100-\mathrm{mL}$ solvent mixture (hexane/acetone, $1: 1, v / v$ ) in $70{ }^{\circ} \mathrm{C}$ water bath. After removing water by $20 \mathrm{~g}$ anhydrous sodium sulfate, extract volume was reduced to $4 \mathrm{~mL}$ by a rotary evaporator. Then, the extract was purified on a silica gel column, containing $2 \mathrm{~g}$ anhydrous sodium sulfate, overlaid with $10 \mathrm{~g}$ activated silica gel (Merck Co., Germany), and topped with $2 \mathrm{~g}$ anhydrous sodium sulfate. Following a pre-rinse of the column with $30-\mathrm{mL}$ solvent mixture (hexane/dichloromethane, $1: 1, v / v)$, the concentrated extract was added to the column and eluted with $70-\mathrm{mL}$ solvent mixture (hexane/dichloromethane, 1:1, v/v). Finally, the final volume of extract was reduced to $1 \mathrm{~mL}$ under a gentler nitrogen gas flow stored in GC vial for analysis.

Details on PAH analytical procedures can be found in our previous studies (Ma et al. 2010; Ma et al. 2009). Sixteen US EPA priority PAHs (naphthalene, acenaphthene, fluorene, phenanthrene, anthracene, fluoranthene, pyrene, benz[a]anthracene, chrysene, benzo[b]fluoranthene, benzo[k]fluoranthene, benzo[a]pyrene, dibenz[a,h]anthracene, indeno[1,2,3-cd]pyrene, and benzo[g,h,i]perylene) (Supelco Co., USA)) were analyzed by an Agilent 6890N GC coupled with Agilent 5973 mass spectrometer detector and a HP-5MS capillary column $(60 \mathrm{~m} \times$ $0.25 \mathrm{~mm} \times 0.25 \mu \mathrm{m}$, Agilent Co., USA). The mass spectrometer was operated under selected ion monitoring (SIM) mode. Two most abundant ions were monitored as the quantification ion and the qualification ion for each compound. Sample extract $(2.0 \mu \mathrm{L})$ was injected in the splitless mode with helium served as the carrier gas. The oven temperature programs were used as follows: held at $90^{\circ} \mathrm{C}$ for $1 \mathrm{~min}$, then raised from 90 to $180^{\circ} \mathrm{C}$ with $10{ }^{\circ} \mathrm{C} \mathrm{min}{ }^{-1}$, held for $1 \mathrm{~min}$, from 180 to $280{ }^{\circ} \mathrm{C}$ at $3{ }^{\circ} \mathrm{C} \mathrm{min}^{-1}$, and held for $20 \mathrm{~min}$. Five levels of standard solutions were used for establishing the calibration curves, and quantification was based on external standard calibration procedure.
Quality assurance/quality control

Strict QA/QC procedures were applied to minimize and quantify sampling/measuring errors. A number of field and laboratory blanks were accompanied during sample collecting and processing. Some low molecule weight PAHs (naphthalene) can be detected in some blanks, and the reported concentrations were all subtracted with blank concentrations. Every ten real samples were treated as one batch, and one real sample was selected for replicate analysis. The results indicated that the variation of PAH concentrations in duplicates was less than $15 \%$. And, for the replicate results, mean values were applied. All the samples (including blanks) were spiked with four surrogates before extraction for checking the performance of the applied method. The recoveries for the four surrogates ranged from 75 to $113 \%$, and all the soil concentrations were corrected with surrogate recoveries. The method detection limit (MDLs) ranged from 0.01 to $0.38 \mathrm{ng} / \mathrm{g}$ for the 16 PAHs, as described in detail in our previous study (Ma et al. 2009).

For statistical analysis, the concentrations below MDLs were set as half of the MDLs for real samples. The onesample Kolmogorov-Smirnov test was applied for the normal distribution testing of concentrations. The Spearman correlation analysis (nonparametric correlation) and the nonparametric Mann-Whitney $U$ test were applied to test correlations and differences between two sets of database. Results were considered statistically significant if the $p$ value was less than 0.05 . All the analysis and testing were performed using SPSS software (version 22.0).

\section{Gridded emission inventory of PAHs}

Gridded emission inventory of PAHs in China in 2005 is integrated by provincial emission inventory with the method developed by Xu et al. (2006). Only a brief description of the method is presented here. Five major emission sources (industrial coal combustion, domestic coal combustion, coke production, straw burning, and firewood burning) are selected. The emission of PAHs is compiled by multiplying the activity rate (annual energy consumption) by PAH emission factors (EFs). The annual energy consumption for each province is obtained from the China Energy Statistical Yearbook officially published in China (National Bureau of Statistics of China 2006). The corresponding PAH EFs of the five sources are obtained from the previous study (Xu et al. 2006). Details of PAH emission for each province in 2005 can be found in Table S1 (Supporting Information, SI). And, the total emission of $\sum_{16} \mathrm{PAHs}$ with the five emission sources is presented in Fig. S1.

Because PAHs are mainly originated from anthropogenic activities, the positive correlation between PAH concentration and human population (human activities) was often observed 
(Garban et al. 2002; Hafner et al. 2005). Population density is often used as surrogate for mapping spatial distribution of PAH emission inventories (Nam et al. 2009). So, the gridded $\mathrm{PAH}$ emission inventories on a $1 / 4^{\circ}$ longitude $\times 1 / 6^{\circ}$ latitude resolution are obtained by using population density dataset on the same resolution as surrogate in this study. The gridded population density distribution in China on a $1 / 4^{\circ}$ longitude $\times$ $1 / 6^{\circ}$ latitude resolution is presented in Fig. S2.

\section{Published data collection}

The literature reviewed here was extracted from the website ISI Web of Knowledge with the following keywords: polycyclic aromatic hydrocarbons (or PAHs), soil, and China. We also selected references with the same keywords from Chinese website of China National Knowledge Infrastructures (CNKI). Then, a comprehensive database of $\mathrm{PAH}$ pollution in Chinese surface soils in the period of 2004-2013 was prepared based on the published results. Along with the database of PAH concentrations in the soil samples collected in 2005, the PAH concentrations in urban soil and rural/ background soil of China are summarized in Table S2 and Table S3, respectively. Totally, 36 and 19 studies were selected for urban soil and rural soil over China. For most studies, the interested target compounds were the 16 US EPA priority PAHs; thus, only the 16 PAHs were selected in this study. All the published PAH concentrations were converted to the unit of nanogram per gram dry weight in the following sections. It should be noted that the measured PAH concentrations were obtained from different groups/laboratories. The applied methodologies for sample collection, treatment, extraction, cleanup, and quantification were different. In this study, all the data collection was based on the assumption that no big differences of the errors caused by the sample process and analyses exist among all the groups/laboratories. The same method was also applied in a previous review study (Cai et al. 2008).

\section{Results and discussion}

Concentration of PAHs in Chinese surface soil samples collected in 2005

The 16 US EPA priority PAHs were analyzed in Chinese surface soil samples, and the detection rates were higher than $98 \%$. The total concentrations (ng/g, dry weight) of the 16 PAHs $\left(\sum_{16}\right.$ PAHs) are summarized in Table 1 . The arithmetic

Table 1 Summary of the 16 PAH concentrations (ng/g dw) in Chinese surface soil in 2005

\begin{tabular}{|c|c|c|c|c|c|c|c|c|c|}
\hline Compounds & Minimum & Fifth percentile & Median & 95th percentile & Maximum & Mean & $\mathrm{SD}$ & Geometrical mean & Detection rate $(\%)$ \\
\hline Naphthalene & 0.98 & 5.16 & 25.3 & 140 & 506 & 43.2 & 63.6 & 23.8 & 100 \\
\hline Acenaphthylene & 0.28 & 0.60 & 1.68 & 12.1 & 124 & 4.52 & 12.5 & 2.06 & 100 \\
\hline Acenaphthene & MDL & 0.46 & 1.51 & 11.5 & 59.0 & 3.41 & 6.49 & 1.74 & 99 \\
\hline Fluorene & 0.41 & 0.71 & 4.01 & 22.3 & 151 & 7.96 & 15.3 & 4.15 & 100 \\
\hline Phenanthrene & 1.20 & 3.73 & 25.1 & 155 & 1,280 & 53.1 & 119 & 24.7 & 100 \\
\hline Anthracene & 0.21 & 0.40 & 1.82 & 12.6 & 88.1 & 4.88 & 11.7 & 2.03 & 100 \\
\hline Fluoranthene & 0.82 & 2.55 & 16.3 & 182 & 735 & 48.0 & 101 & 18.0 & 100 \\
\hline Pyrene & 0.54 & 1.59 & 10.4 & 136 & 509 & 35.2 & 74.5 & 12.2 & 100 \\
\hline Benz[a]anthracene & 0.15 & 0.49 & 5.41 & 86.4 & 280 & 20.4 & 45.0 & 5.57 & 100 \\
\hline Chrysene & 0.50 & 1.23 & 12.5 & 110 & 562 & 30.6 & 62.8 & 11.9 & 100 \\
\hline Benzo[b]fluoranthene & 0.31 & 1.77 & 14.8 & 173 & 739 & 43.2 & 94.5 & 14.4 & 100 \\
\hline Benzo[k]fluoranthene & 0.07 & 0.32 & 2.96 & 39.0 & 118 & 8.82 & 18.6 & 3.08 & 100 \\
\hline Benzo[a]pyrene & MDL & 0.24 & 3.13 & 66.7 & 289 & 16.6 & 43.0 & 3.53 & 99 \\
\hline Indeno[1,2,3-cd]pyrene & 0.19 & 1.09 & 8.55 & 115 & 382 & 26.7 & 55.6 & 8.97 & 100 \\
\hline Dibenz[a,h]anthracene & MDL & 0.27 & 1.85 & 23.4 & 167 & 6.30 & 17.8 & 1.95 & 98 \\
\hline Benzo[g,h,i]perylene & MDL & 0.51 & 7.67 & 118 & 306 & 24.3 & 49.6 & 7.81 & 99 \\
\hline Two-ring PAHs & 0.98 & 5.16 & 25.3 & 140 & 506 & 43.2 & 63.6 & 23.8 & - \\
\hline Three-ring PAHs & 2.57 & 6.49 & 35.2 & 208 & 1,640 & 73.9 & 158 & 36.2 & - \\
\hline Four-ring PAHs & 2.04 & 6.62 & 44.5 & 529 & 2,040 & 134 & 280 & 48.9 & - \\
\hline Five-ring PAHs & 0.55 & 3.06 & 23.5 & 301 & 1,260 & 74.9 & 171 & 24.0 & - \\
\hline Six-ring PAHs & 0.38 & 2.04 & 16.7 & 223 & 687 & 51.0 & 105 & 17.5 & - \\
\hline$\sum_{16} \mathrm{PAHs}$ & 9.90 & 32.5 & 159 & 1,310 & 5,910 & 377 & 718 & 176 & - \\
\hline
\end{tabular}

$M D L$ method detection limit, $S D$ standard deviation 
mean concentration of $\sum_{16} \mathrm{PAHs}$ was $377 \pm 718 \mathrm{ng} / \mathrm{g}$ for all the 157 samples (with the median value and the geometrical mean of 159 and $176 \mathrm{ng} / \mathrm{g}$, respectively), ranged from 9.90 to $5,911 \mathrm{ng} / \mathrm{g}$ with a variation of three orders of magnitude. The lowest and highest concentrations of $\sum_{16} \mathrm{PAHs}$ were found in background site and urban site, respectively, which is expected since there are much more sources in urban areas than background areas. Arithmetic mean, standard deviation, geometrical mean, median, 5 th percentile, 95 th percentile, and minimum and maximum values are also summarized in Table 1 for individual PAHs. Phenanthrene, naphthalene, fluoranthene, and benzo[b]fluoranthene are the most predominant compounds in Chinese surface soil. Significant correlations (Spearman correlation analysis) were found among all PAHs $(p<0.01)$, which can be found in details in Table S4. Furthermore, the correlation coefficients among highmolecular-weight PAHs (greater than four rings) were higher than 0.85 . The significant correlation indicated their similar sources, which was consistent with the results of a previous study (Chung et al. 2007). For most PAHs, the concentrations showed a wide range with almost three orders of magnitude difference between the minimum and the maximum concentrations (Table 1). The large difference should be attributed to the locations of the sites and its closeness to sources (Morillo et al. 2007). In terms of the compositional profiles (Fig. S3), four-ring PAHs were the dominant group, which accounted for 31 and $30 \%$ for urban and rural samples, respectively. Four-ring PAHs were mainly released from the incomplete combustion of organic materials (Morillo et al. 2007). However, for background samples, higher proportion of two-ring PAHs was found (30 \%). It was expected as low ring PAHs are easily transported for longer distance via atmosphere than high ring PAHs. The observed compositional difference clearly indicated the different sources of PAHs in urban/rural and background areas. The arithmetic mean concentrations of $\sum_{16} \mathrm{PAHs}$ (in $\mathrm{ng} / \mathrm{g}$ ) were $617 \pm 936,340 \pm 676$, and $126 \pm 74$ for the urban, rural, and background surface soils in China, respectively, showing the typical primary distribution pattern (Jia et al. 2010; Li et al. 2010b). Generally, the concentrations of PAHs in large cities and developed regions in Eastern China were higher than those in other regions. According to the European classification system of soil contamination (Maliszewska-Kordybach 1996), the $\sum_{16} \mathrm{PAH}$ concentrations of $<200 ; 200-600 ; 600-1,000$; and $>1,000 \mathrm{ng} / \mathrm{g}$ could be attributed to noncontaminated, weakly contaminated, contaminated, and heavily contaminated, respectively. Therefore, $85 \%$ of the studied soil samples were considered to be weakly contaminated, and only $7 \%$ were considered as heavily contaminated soil for the soil samples collected in 2005.

Comparison with PAH levels in soil in other countries is important for understanding the pollution status in China with a global context. When compared with some typical urban regions worldwide, the concentrations of PAHs in Chinese urban soils are comparable with some Asian countries and lower than some European and American countries (Mielke et al. 2001). For example, the total concentrations (in ng/g dry weight (dw)) of PAHs were 11,930; 1,990; and 989 in the UK, Italy, and Slovenia, respectively (Morillo et al. 2007), and 380 in Thailand (Wilcke et al. 1999). For rural soils in China, the concentration of PAHs is consistent with the national scale studies in Korea and the UK. For example, the average concentration of total PAHs in 226 agriculture soil samples collected in South Korea was $236 \mathrm{ng} / \mathrm{g}$ dw (Nam et al. 2003). The average concentration of total PAHs from 200 rural soil samples collected on the national scale in the UK was $976 \mathrm{ng} / \mathrm{g} \mathrm{dw}$ (Heywood et al. 2006), which was three times higher than that in the present study. For the large scale of background soil study, the average concentrations of total PAHs were 640 and $150 \mathrm{ng} / \mathrm{g} \mathrm{dw}$ in the UK and Norway, respectively (Nam et al. 2008), which are both higher than those in the present study. Furthermore, it was found that the mean concentration of PAHs was $328 \mathrm{ng} / \mathrm{g}$ in 108 global background soil samples in 1998, and only $65 \mathrm{ng} / \mathrm{g}$ was measured for Asian samples (without China), which was lower than the result in the present study (Nam et al. 2009).

\section{Influencing factors}

As we discussed in the previous section, the concentration of PAHs in Chinese surface soil showed a primary distribution pattern, as higher in the source regions (urban sites) and lower in the regions far away from the sources (background sites). Based on the findings, the primary source (emission of PAHs) is considered as the major influential factor on PAH concentration and distribution in Chinese surface soil. The other influential factors, such as the SOC, may also play some roles on PAH distribution, and the relationship between the concentration of PAHs and SOC was also studied.

In order to study the relationship between PAH emission and the PAH concentration in Chinese soil, we compiled emission inventory for the year of 2005. In according to the annual consumption, the industrial coal combustion was predominant in China in 2005. However, the industrial coal combustion had the lowest contribution to the total PAH emission (see Fig. S1), which was expected due to its higher combustion efficiency and lower EFs (Xu et al. 2006). Domestic coal combustion, straw burning, and firewood burning were the three predominated emission sources of PAHs in China, which contributed more than $85 \%$ of the total emission of PAHs in 2005. In China, the farm wastes (straw and firewood) are usually used as fuels for cooking and heating in rural area, and sometimes, they were burned in field, which cause high PAH emission ( $\mathrm{Lu}$ et al. 2009). Low burning rate is the main reason for producing severe PAH emission for domestic coal combustion 
in China (Shen et al. 2010). The total emission of 16 PAHs was 32,900 $t$ in China in 2005, which was higher than that 25,300 in 2003 (Xu et al. 2006), indicating the increasing of PAH emission in the past 2 years.

Gridded PAH emission inventory with a $1 / 4^{\circ}$ longitude $\times 1 /$ $6^{\circ}$ latitude resolution is presented in Fig. 2. Generally, relatively higher PAH emission inventory was found in Eastern China, especially in the provinces around Bohai Bay, the Yangtze River Delta, and the Pearl River Delta. The PAH emission inventory in east part of Sichuan was also high, which is consistent with a previous study (Xu et al. 2006). PAH emission inventory in the eastern provinces was one order of magnitude higher than that in the western provinces in China. The western and northern four provinces (Xizang, Inner Mongolia, Xinjiang, and Qinghai) had the lowest emissions of PAHs due to their lowest population density and social-economic development. The measured PAH concentrations of the soil samples collected in 2005 were compared with emission inventory in the same grid cells that the sampling sites located. Exclude from some outliers, significantly positive correlation $(p<0.001)$ was found between these two datasets. The result indicated that PAH emission was the important factor influencing PAH concentration in Chinese surface soil, which is called the primary distribution pattern (Li et al. 2010b). A significantly positive correlation $(p<0.05)$ between emission inventory and measured PAH concentration in soil was also observed in the North China Plain (Wang et al. 2012). These studies revealed that concentrations and distributions of PAHs in surface soils were highly dependent on their emissions (Wang et al. 2012).

$\mathrm{SOC}$ is a dominant factor for sorption, sequestration, and fate of organic compounds (Jiang et al. 2009; Sweetman et al. 2005). For PAH pollution, SOC was also a key role to keep storage of PAHs, which was well studied in large-scale monitoring programs (Heywood et al. 2006; Nam et al. 2008). The relationship between $\sum_{16} \mathrm{PAH}$ concentration and SOC was

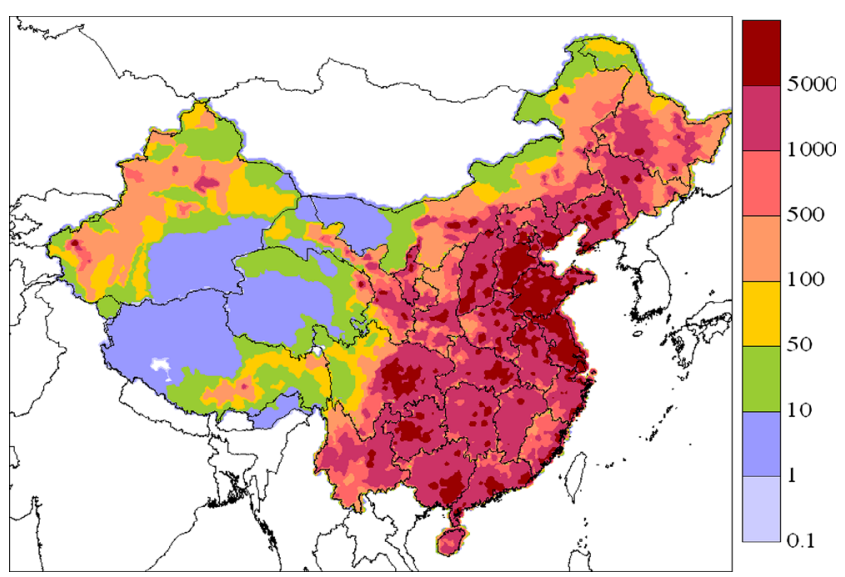

Fig. 2 Gridded emission inventory of $\sum_{16} \mathrm{PAHs}$ with a $1 / 4^{\circ}$ longitude $\times 1$ / $6^{\circ}$ latitude resolution in China in 2005 (kg/cell) also studied. No obvious correlation was found between PAH concentration $(\mathrm{ng} / \mathrm{g} \mathrm{dw})$ and SOC (\%). Similarly, no correlation was found between soil organic matter content and the total PAH concentrations in British soils (Heywood et al. 2006). This is not unexpected, since PAHs in Chinese surface soil was still showing the primary distribution pattern, and the influence of the SOC (one of the two factors for the secondary distribution pattern, another one is the temperature) on the distribution of PAHs in surface soil was not stronger than the primary sources to force PAHs in soil to be correlated with its contents on a national scale (Li et al. 2010b). However, when the PAH concentration and SOC content were natural $\log$ transformed, significant positive correlation was found $(p<0.0001)$. This kind of correlation between PAH concentration and SOC was also observed in surface soils in the North China Plain (Wang et al. 2010).

\section{Geographical distribution of PAH concentration in China}

PAH pollution in Chinese surface soil has been attracted more attention in the past decades, and a large number of datasets on PAH concentrations were reported, which makes it possible to establish the geographical distribution of PAHs in surface soil on the national scale in China. In order to obtain comprehensive information, we compiled a dataset containing not only the results of this study, but also all the available published data on PAH concentration in Chinese surface soil in the past 10 years (2004-2013) as well. Based on the database, the geographical distributions of PAH concentration in urban soil and rural/background soil in China were established and discussed in the following sections.

\section{PAH distribution in urban soil in China}

The geographical distribution of the total concentrations of PAHs $\left(\sum_{16} \mathrm{PAHs}\right)$ in Chinese urban surface soil determined in the period of 2004-2013 is shown in Fig. 3. The observed PAH concentrations in surface soil remarkably varied from different regions in China. Generally, higher concentration was found in Eastern China and lower in Middle and Western China. Concentrations spanned up to three orders of magnitude between the minimum and maximum concentrations of $\sum_{16}$ PAHs. The concentrations of $\sum_{16} \mathrm{PAHs}$ in Chinese urban surface soils were in the range of 30.1 to $23,300 \mathrm{ng} / \mathrm{g}$, with the geometrical mean and the median values of 584 and $661 \mathrm{ng} / \mathrm{g}$, respectively. Relatively higher concentrations were found in the capital cities of Ji'nan (the capital of Shandong Province, thereafter), Taiyuan (Shanxi), Urumqi (Xinjiang), Beijing (the capital city of China), Shanghai (Shanghai), Harbin (Heilongiiang), and Chengdu (Sichuan), which were also marked as "hotspot" with estimated emission inventory (Zhang et al. 2007). In these capital cities, the concentrations of $\sum_{16} \mathrm{PAHs}$ were higher than 
Fig. 3 Geographical distribution of $\sum_{16}$ PAHs in Chinese urban soil

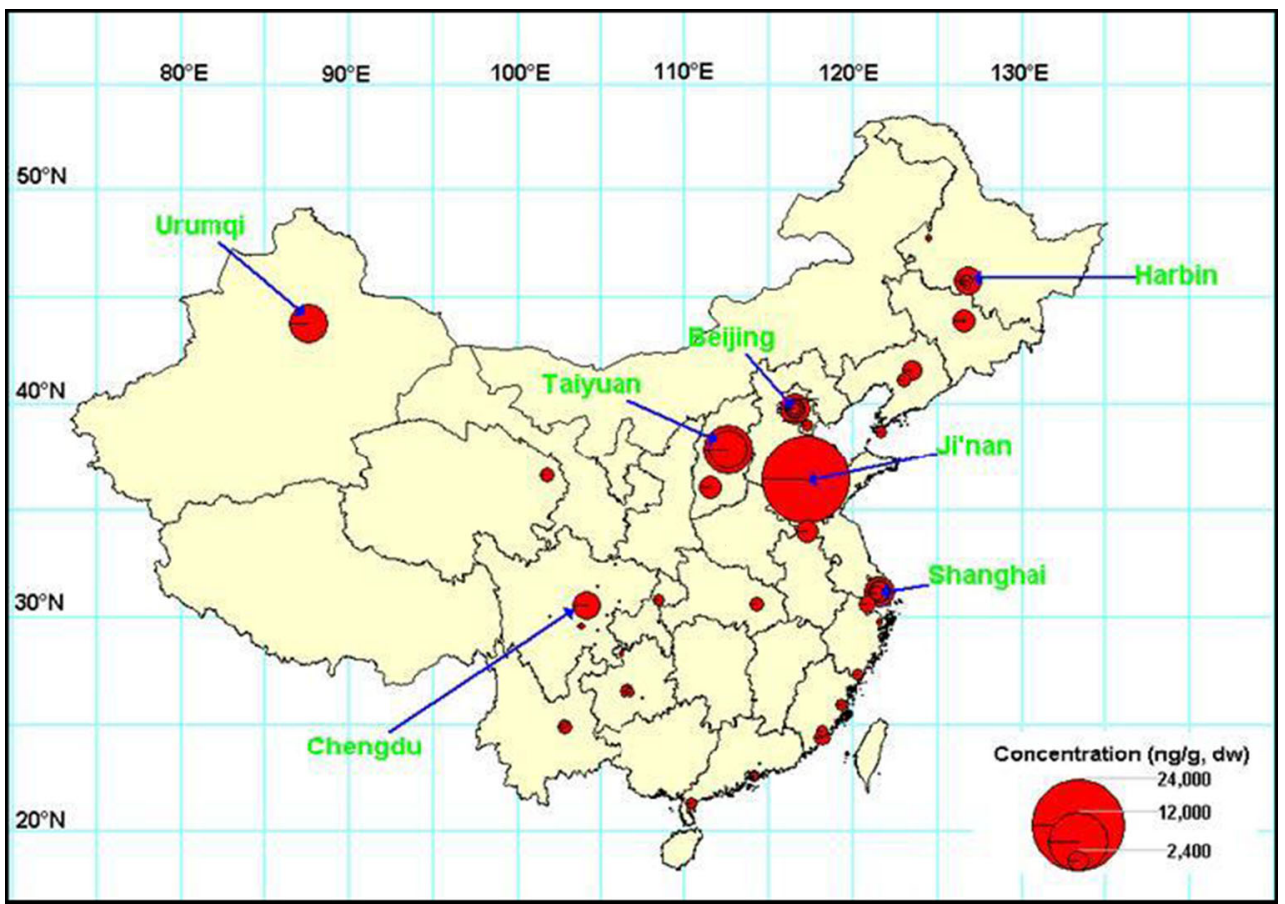

2,400 ng/g. According to the European classification system of soil contamination (Maliszewska-Kordybach 1996), all the soil samples are characterized as heavily contaminated, indicating the high health risk for local people. It is expected since there are heavy traffic and higher population density in these large cities in China (Peng et al. 2011). The more anthropogenic activities exist, the more PAH emission is released into environment. The spatial distribution of concentration was consistent with that of emission inventory of PAH in China. For PAH emission, major cities usually stand out as the emission centers, especially the capital cities of Chinese provinces (Zhang et al. 2007). However, for some urban areas, very low PAH concentration was also observed (see Fig. 3), which may be explained by the special sampling locations and socialeconomic statuses of these sites. Furthermore, the systematic errors caused by the sample process and analysis should be also considered for deeply tracing the reasons.
Fig. 4 Geographical distribution of $\sum_{16}$ PAHs in Chinese rural soil

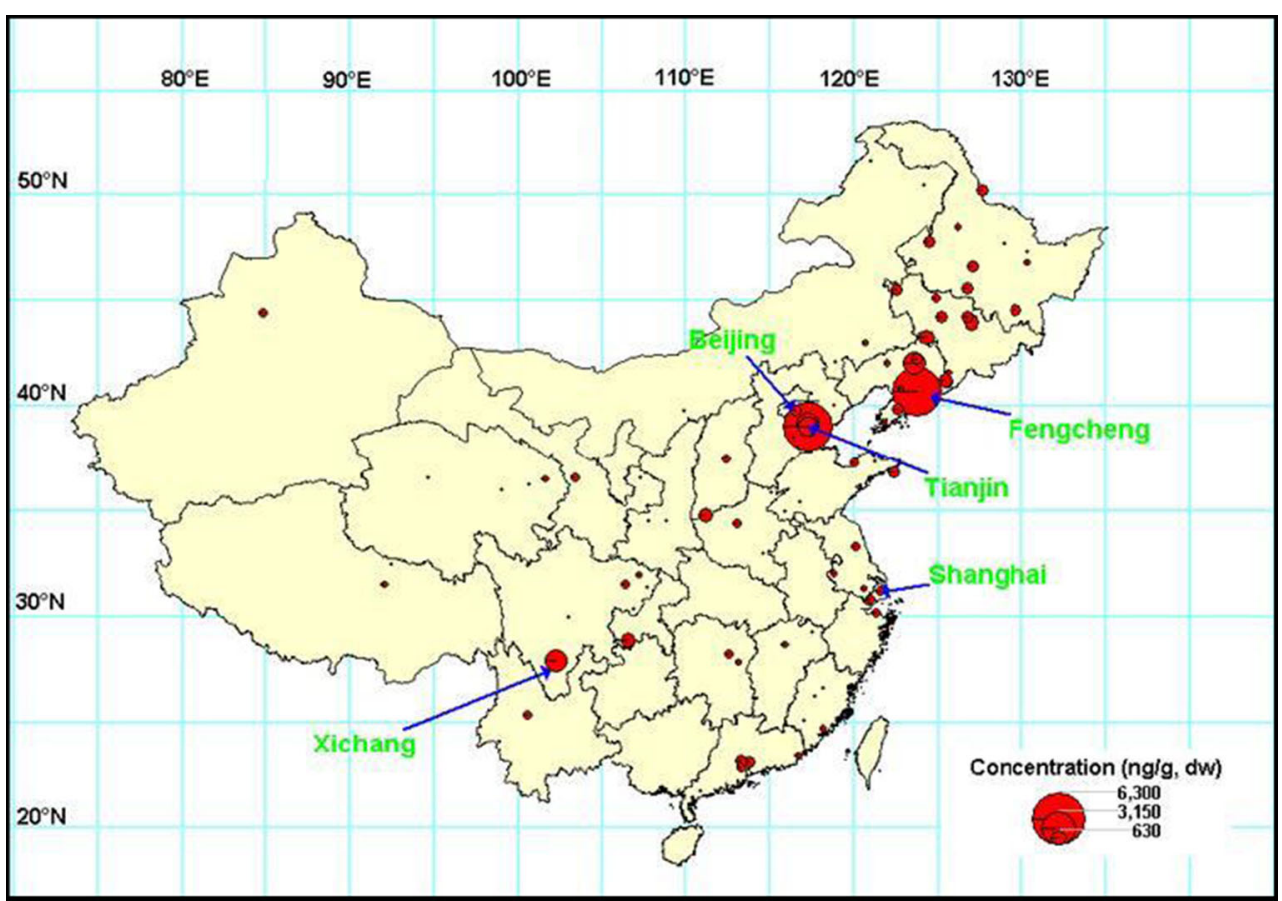




\section{PAH distribution in rural soil in China}

The geographical distribution of PAH concentration in rural (agricultural) soil determined in the period of 2004-2013 is presented in Fig. 4. Totally, almost 100 sampling sites,' areas,' and regions' results were summarized. The concentrations of $\sum_{16} \mathrm{PAHs}$ ranged from 3.70 to $6,250 \mathrm{ng} / \mathrm{g}$ with the geometrical mean and the median values of 147 and $148 \mathrm{ng} / \mathrm{g}$, respectively. The concentration range also spanned up to three orders of magnitude, indicating the variable pollution levels of PAHs in rural areas in China. It should be noted that there were two special areas (outliers) with the highest concentrations of PAHs; one is located in Tianjin, and the other one is located in Fengcheng, Liaoning Province. The former one is located in the vicinity of a number of pollution sources, including large-scale coal-burning boiler and factories (Tao et al. 2004). Furthermore, the soil has been irrigated with wastewater for more than 40 years (Tao et al. 2004). So, the extremely high PAH pollution can be explained by these two reasons. However, for the latter one in Fengcheng, except for the long-term heating season, no other explanation was found. If the results of these two areas were excluded for the statistical analysis, the geometrical mean concentration of $\sum_{16} \mathrm{PAHs}$ was $136 \mathrm{ng} /$ g, which was lower than the average concentration of $\sum_{16}$ PAHs (236 ng/g) in Korea (Nam et al. 2003). According to the classification of soil contamination, this concentration can be characterized as noncontaminated soil (MaliszewskaKordybach 1996). The concentration of $\sum_{16} \mathrm{PAHs}$ in rural soils was lower than that in urban soils by a factor of 4 , indicating a relatively higher PAH exposure for urban residents in China. The nonparametric Mann-Whitney $U$ test also confirmed the significant difference between the concentrations of PAHs in Chinese urban soil and rural soil $(p<0.0001)$. Generally, the Northeast China (such as Heilongjiang Province, Jilin Province, and Liaoning Province) has notably higher PAH concentration than those of other parts of China. In rural areas of the three provinces, most of the energies for cooking and space heating are from straw and firewood combustion. The combustion of biomass might be the reason for the higher PAH pollution in soil in these regions. As pointed out in a previous study, biomass burning contributed $56 \%$ of the total emission of PAHs in China in 2003 (Xu et al. 2006). It was also found that indoor straw and firewood combustions were the most important sources for PAH pollution in rural areas in China (Zhang et al. 2008). Except for the above regions, relatively higher concentrations of PAHs were also

Table 2 Concentrations of $\sum_{16} \mathrm{PAHs}(\mathrm{ng} / \mathrm{g} \mathrm{dw})$ in riverbank soil in China

\begin{tabular}{|c|c|c|c|c|}
\hline Location & Soil type & No of PAHs & Concentration & Reference \\
\hline Zhejiang Province & Riverbank & 15 & $350(85.2-676)$ & Zhu et al. (2008) \\
\hline Hangzhou City, Zhejiang & Water body bank & 10 & $298(59.7-616)$ & Chen et al. (2004) \\
\hline The Guanting Reservoir & Water source & 16 & $394(62.8-4,110)$ & Jiao et al. (2009) \\
\hline The Pearl River Delta & Watershed & 16 & $315(58-3,080)$ & Ma et al. (2008) \\
\hline The Pearl River Delta & Agricultural & 16 & $317(\mathrm{ND}-4,080)$ & Li et al. (2007) \\
\hline The Pearl River Delta & Vegetable & 16 & $1,480(160-3,700)$ & Cai et al. (2007) \\
\hline The Pearl River Delta & Crop, paddy, nature & 16 & $192(28.0-711)$ & Liu et al. (2011) \\
\hline The Aojiang River & River bank & 15 & $1,180(397-1,930)$ & Li et al. (2010a) \\
\hline The Yellow River Delta & Rural, suburban, urban & 16 & $360(181-2,170)$ & Xie et al. (2012) \\
\hline The Yellow River Delta & NA & 16 & $432(70.6-1,830)$ & Yuan et al. (2011) \\
\hline The Yangtze River Delta & NA & 15 & $397(8.6-3,880)$ & Ping et al. (2007) \\
\hline The Yangtze River Delta & Valley & 16 & $33.2(0-530)$ & Xing et al. (2006) \\
\hline The Yangtze River Delta & Agricultural & 15 & $296(128-604)$ & Ni et al. (2008) \\
\hline The Songhua River Basin & River bank & 15 & $209(30.1-870)$ & Ma et al. (2013) \\
\hline The Liaohe Estuarine Wetland & Wetland & 16 & $852(293-1,940)$ & Liao et al. (2011) \\
\hline The Liao River Basin & NA & 16 & $2,290(285-8,350)$ & Song et al. (2008) \\
\hline The Yanhe River Basin & Agricultural & 16 & 73.7 & Li et al. (2011) \\
\hline The Dongjiang River Basin & Rural & 17 & $116(23.5-231)$ & Zheng et al. (2014) \\
\hline The watershed of Bohai Sea & NA & 16 & 546 & Zuo et al. (2006) \\
\hline The watershed of Bohai Sea & NA & 16 & $546(27.9-8,430)$ & Zuo et al. (2007) \\
\hline The Baiyangdian area & Agricultural & 16 & $417(146-646)$ & Zhao et al. (2009a) \\
\hline The Daqing River Basin & NA & 16 & $405(54.2-3,230)$ & Zhao et al. (2009b) \\
\hline
\end{tabular}

$N A$ not available, $N D$ not detected 
found in Beijing-Tianjin and surrounding areas. This region has rapid social-economic development, so the enhanced energy consumption might be the reason for the higher PAH concentration in this region (Wang et al. 2010). Higher emission intensity of PAHs was also found in this region in the present study (see Fig. 2) and in a previous study ( $\mathrm{Xu}$ et al. 2006).

\section{PAH distribution in riverbank soil in China}

Wastewater discharge from domestic and industrial activities is one of the major sources of PAHs, especially for rivers crossing big cities (Chen et al. 2004; Ma et al. 2008). In China, there are some major rivers for drinking water resources, like the Pearl River Delta, the Yangtze River Delta, and the Songhua River Basin. For these rivers, most studies were focused on PAH contamination in water and sediment, with only a little portion related to PAH pollution in riverbank soil. An overview of the results of PAH pollution in riverbank soil in China is summarized in Table 2. Most of the collected riverbank soils were used for agriculture. Similarly, differences with two orders of magnitude were observed with PAH concentrations among different rivers, indicating the various pollution levels of PAHs. The concentrations of $\sum_{16} \mathrm{PAHs}$ ranged from 33.2 to $2,290 \mathrm{ng} / \mathrm{g}$, with the geometrical mean and the median values of 337 and $360 \mathrm{ng} / \mathrm{g}$, respectively, which were significantly higher than the concentration of $\sum_{16} \mathrm{PAHs}$ in Chinese rural soils $(p<0.0001$, the nonparametric MannWhitney $U$ test). According to the above-mentioned classification, this concentration can be considered as weakly contaminated (Maliszewska-Kordybach 1996). The highest and lowest concentrations of PAHs were observed in the Liao River Basin and the Yangtze River Delta, respectively. For the highest concentration, it is expected because the Liao River Basin is an important industrial and mining area of Northeast China (Song et al. 2008). However, for the Yangtze River Delta, one order of magnitude difference was found among different studies. The major influential factor may be the different sampling locations. Furthermore, it should be noted that the comparison was made by the reported results of literature without any corrections. Some other unknown factors should be considered for further discussion and comparison, such as treatment methods and sampling years/seasons.

\section{Conclusions}

Based on the results of the 157 surface soil samples collected in 2005 and other literature over the past 10 years (20042013), the occurrence and geographical distribution of PAHs in Chinese surface soil were comprehensively studied. PAHs were detected in soils from urban, rural/agricultural regions, and river basins, which indicated the ubiquitous contamination of PAHs throughout China. Generally, most of urban soil samples were characterized as contaminated, and most of rural/agricultural soil samples were characterized as weakly contaminated. An obvious geographical distribution with PAH concentration was found, as higher in Eastern China and lower in Middle and Western China. This study provided a basic database with PAH concentration on the national scale of China. The result of this study is beneficial to make relevant policies to control PAH pollution in China. Furthermore, population exposure assessment and the national and/or global scale transport of PAH from China will be studied according to the results of this study in future.

Acknowledgments This study was supported by the National Natural Science Foundation of China (No. 41101493, 41101495, and 21277038). Financial supports from the China Postdoctoral Science Foundation Funded Project (No. 2011M500677) and the Fundamental Research Funds for the Central Universities (Grant No. HIT. NSRIF. 2014095) are highly appreciated. We are grateful to volunteers for helping with soil sampling nationwide in China, especially the teachers and students at the Harbin Institute of Technology, Dalian Maritime University, Chengdu University of Technology, and Northeast Forestry University.

\section{References}

Bucheli TD, Blum F, Desaules A, Gustafsson Ö (2004) Polycyclic aromatic hydrocarbons, black carbon, and molecular markers in soils of Switzerland. Chemosphere 56:1061-1076

Cai Q-Y, Mo C-H, Li Y-H, Zeng Q-Y, Katsoyiannis A, Wu Q-T et al (2007) Occurrence and assessment of polycyclic aromatic hydrocarbons in soils from vegetable fields of the Pearl River Delta, South China. Chemosphere 68:159-168

Cai Q-Y, Mo C-H, Wu Q-T, Katsoyiannis A, Zeng Q-Y (2008) The status of soil contamination by semivolatile organic chemicals (SVOCs) in China: a review. Sci Total Environ 389:209-224

Chen B, Xuan X, Zhu L, Wang J, Gao Y, Yang K et al (2004) Distributions of polycyclic aromatic hydrocarbons in surface waters, sediments and soils of Hangzhou City, China. Water Res 38:35583568

Chung MK, Hu R, Cheung KC, Wong MH (2007) Pollutants in Hong Kong soils: polycyclic aromatic hydrocarbons. Chemosphere 67: 464-473

Dimashki M, Lim LH, Harrison RM, Harrad S (2001) Temporal trends, temperature dependence, and relative reactivity of atmospheric polycyclic aromatic hydrocarbons. Environ Sci Technol 35:22642267

Garban B, Blanchoud H, Motelay-Massei A, Chevreuil M, Ollivon D (2002) Atmospheric bulk deposition of PAHs onto France: trends from urban to remote sites. Atmos Environ 36:5395-5403

Hafner WD, Carlson DL, Hites RA (2005) Influence of local human population on atmospheric polycyclic aromatic hydrocarbon concentrations. Environ Sci Technol 39:7374-7379

Heywood E, Wright J, Wienburg CL, Black HIJ, Long SM, Osborn D et al (2006) Factors influencing the national distribution of polycyclic aromatic hydrocarbons and polychlorinated biphenyls in British soils. Environ Sci Technol 40:7629-7635 
Inomata Y, Kajino M, Sato K, Ohara T, Kurokawa J-I, Ueda $\mathrm{H}$ et al (2012) Emission and atmospheric transport of particulate PAHs in Northeast Asia. Environ Sci Technol 46:4941-4949

Jia H, Liu L, Sun Y, Sun B, Wang D, Su Y et al (2010) Monitoring and modeling endosulfan in Chinese surface soil. Environ Sci Technol 44:9279-9284

Jiang Y-F, Wang X-T, Wang F, Jia Y, Wu M-H, Sheng G-Y et al (2009) Levels, composition profiles and sources of polycyclic aromatic hydrocarbons in urban soil of Shanghai, China. Chemosphere 75: $1112-1118$

Jiao W, Lu Y, Wang T, Li J, Han J, Wang G et al (2009) Polycyclic aromatic hydrocarbons in soils around Guanting Reservoir, Beijing, China. Chem Ecol 25:39-48

Lang C, Tao S, Liu W, Zhang Y, Simonich S (2008) Atmospheric transport and outflow of polycyclic aromatic hydrocarbons from China. Environ Sci Technol 42:5196-5201

Li Y, Li F, Zhang T, Yang G, Chen J, Wan H (2007) Pollution assessment, distribution and sources of PAHs in agricultural soils of Pearl River Delta - the biggest manufacturing base in China. J Environ Sci Health A 42:1979-1987

Li J, Shang X, Zhao Z, Tanguay RL, Dong Q, Huang C (2010a) Polycyclic aromatic hydrocarbons in water, sediment, soil, and plants of the Aojiang River waterway in Wenzhou, China. J Hazard Mater 173:75-81

Li Y-F, Harner T, Liu L, Zhang Z, Ren N-Q, Jia H et al (2010b) Polychlorinated biphenyls in global air and surface soil: distributions, air-soil exchange, and fractionation effect. Environ Sci Technol 44:2784-2790

Li Q, Huang T, Shang X, Xue K (2011) Distribution and sources of polycyclic aromatic hydrocarbon (PAHs) pollutants in soils of Yanhe River basin, north of Shaanxi province. J Shaanxi Norm Univ (Nat Sci Ed) 39:76-80, in Chinese

Liao S-L, Lang Y-H, Wang Y-S (2011) Distribution and sources of PAHs in soil from Liaohe estuarine wetland. Environ Sci 32:1094-1100, in Chinese

Liu G, Yu L, Li J, Liu X, Zhang G (2011) PAHs in soils and estimated airsoil exchange in the Pearl River Delta, South China. Environ Monit Assess 173:861-870

Lu H, Zhu L, Zhu N (2009) Polycyclic aromatic hydrocarbon emission from straw burning and the influence of combustion parameters. Atmos Environ 43:978-983

Ma LL, Chu SG, Wang XT, Cheng HX, Liu XF, Xu XB (2005) Polycyclic aromatic hydrocarbons in the surface soils from outskirts of Beijing, China. Chemosphere 58:1355-1363

Ma X, Ran Y, Gong J, Zou M (2008) Concentrations and inventories of polycyclic aromatic hydrocarbons and organochlorine pesticides in watershed soils in the Pearl River Delta, China. Environ Monit Assess 145:453-464

Ma WL, Li YF, Sun DZ, Qi H (2009) Polycyclic aromatic hydrocarbons and polychlorinated biphenyls in topsoils of Harbin, China. Arch Environ Contam Toxicol 57:670-678

Ma W-L, Li Y-F, Qi H, Sun D-Z, Liu L-Y, Wang D-G (2010) Seasonal variations of sources of polycyclic aromatic hydrocarbons (PAHs) to a northeastern urban city, China. Chemosphere 79:441-447

Ma W-L, Liu L-Y, Qi H, Zhang Z-F, Song W-W, Shen J-M et al (2013) Polycyclic aromatic hydrocarbons in water, sediment and soil of the Songhua River Basin, China. Environ Monit Assess 185:8399-8409

Maliszewska-Kordybach B (1996) Polycyclic aromatic hydrocarbons in agricultural soils in Poland: preliminary proposals for criteria to evaluate the level of soil contamination. Appl Geochem 11:121-127

Mastral AM, Callen MS (2000) A review on polycyclic aromatic hydrocarbon $(\mathrm{PAH})$ emissions from energy generation. Environ Sci Technol 34:3051-3057

Mielke HW, Wang G, Gonzales CR, Le B, Quach VN, Mielke PW (2001) $\mathrm{PAH}$ and metal mixtures in New Orleans soils and sediments. Sci Total Environ 281:217-227
Morillo E, Romero AS, Maqueda C, Madrid L, Ajmone-Marsan F, Grcman H et al (2007) Soil pollution by PAHs in urban soils: a comparison of three European cities. J Environ Monit 9:1001-1008

Nam JJ, Song BH, Eom KC, Lee SH, Smith A (2003) Distribution of polycyclic aromatic hydrocarbons in agricultural soils in South Korea. Chemosphere 50:1281-1289

Nam JJ, Thomas GO, Jaward FM, Steinnes E, Gustafsson O, Jones KC (2008) PAHs in background soils from Western Europe: influence of atmospheric deposition and soil organic matter. Chemosphere 70: $1596-1602$

Nam JJ, Sweetman AJ, Jones KC (2009) Polynuclear aromatic hydrocarbons (PAHs) in global background soils. J Environ Monit 11:45-48

National Bureau of Statistics of China (2006) China Energy Statistical Yearbook 2005. China Statistics Press, Beijing

Ni JZ, Luo YM, Wei R, Li XH (2008) Distribution of polycyclic aromatic hydrocarbons in particle-size separates and density fractions of typical agricultural soils in the Yangtze River Delta, East China. Eur J Soil Sci 59:1020-1026

Peng C, Chen W, Liao X, Wang M, Ouyang Z, Jiao W et al (2011) Polycyclic aromatic hydrocarbons in urban soils of Beijing: status, sources, distribution and potential risk. Environ Pollut 159:802-808

Ping LF, Luo YM, Zhang HB, Li QB, Wu LH (2007) Distribution of polycyclic aromatic hydrocarbons in thirty typical soil profiles in the Yangtze River Delta region, east China. Environ Pollut 147:358 365

Primbs T, Piekarz A, Wilson G, Schmedding D, Higginbotham C, Field J et al (2008) Influence of Asian and Western United States urban areas and fires on the atmospheric transport of polycyclic aromatic hydrocarbons, polychlorinated biphenyls, and fluorotelomer alcohols in the Western United States. Environ Sci Technol 42:63856391

Ravindra K, Sokhi R, Van Grieken R (2008) Atmospheric polycyclic aromatic hydrocarbons: source attribution, emission factors and regulation. Atmos Environ 42:2895-2921

Ren N, Que M, Li Y-F, Liu Y, Wan X, Xu D et al (2007) Polychlorinated biphenyls in Chinese surface soils. Environ Sci Technol 41:38713876

Shen G, Wang W, Yang Y, Zhu C, Min Y, Xue M et al (2010) Emission factors and particulate matter size distribution of polycyclic aromatic hydrocarbons from residential coal combustions in rural Northern China. Atmos Environ 44:5237-5243

Song X-y, Sun L-n, Yang X-b, Qu Y-j, Sun T-h (2008) Contamination status of polycyclic aromatic hydrocarbon in topsoils of Liao River Basin. J Agro-Environ Sci 27:216-220, in Chinese

Srogi K (2007) Monitoring of environmental exposure to polycyclic aromatic hydrocarbons: a review. Environ Chem Lett 5: 169-195

Sweetman AJ, Valle MD, Prevedouros K, Jones KC (2005) The role of soil organic carbon in the global cycling of persistent organic pollutants (POPs): interpreting and modelling field data. Chemosphere 60:959-972

Tao S, Cui YH, Xu FL, Li BG, Cao J, Liu WX et al (2004) Polycyclic aromatic hydrocarbons (PAHs) in agricultural soil and vegetables from Tianjin. Sci Total Environ 320:11-24

Tao S, Wang W, Liu W, Zuo Q, Wang X, Wang R et al (2011) Polycyclic aromatic hydrocarbons and organochlorine pesticides in surface soils from the Qinghai-Tibetan plateau. J Environ Monit 13:175181

Wang XP, Yao TD, Cong ZY, Yan XL, Kang SC, Zhang Y (2007) Concentration level and distribution of polycyclic aromatic hydrocarbons in soil and grass around Mt. Qomolangma, China. Chin Sci Bull 52:1405-1413

Wang W, Massey Simonich SL, Xue M, Zhao J, Zhang N, Wang R et al (2010) Concentrations, sources and spatial distribution of polycyclic aromatic hydrocarbons in soils from Beijing, Tianjin and surrounding areas. North China Environ Pollut 158:1245-1251 
Wang X, Zuo Q, Duan Y, Liu W, Cao J, Tao S (2012) Factors affecting spatial variation of polycyclic aromatic hydrocarbons in surface soils in North China Plain. Environ Toxicol Chem 31:2246-2252

Wilcke W (2000) Synopsis polycyclic aromatic hydrocarbons (PAHs) in soil-a review. J Plant Nutr Soil Sci 163:229-248

Wilcke W (2007) Global patterns of polycyclic aromatic hydrocarbons (PAHs) in soil. Geoderma 141:157-166

Wilcke W, Müller S, Kanchanakool N, Niamskul C, Zech W (1999) Polycyclic aromatic hydrocarbons in hydromorphic soils of the tropical metropolis Bangkok. Geoderma 91:297-309

Xie W, Chen A, Li J, Liu Q, Yang H, Lu Z (2012) County-scale distribution of polycyclic aromatic hydrocarbons in topsoil of the Yellow River Delta Region. J Environ Sci Health A 47:1419-1427

Xing W, Luo Y, Wu L, Song J, Qian W, Christie P (2006) Spatial distribution of PAHs in a contaminated valley in Southeast China. Environ Geochem Health 28:89-96

$\mathrm{Xu} \mathrm{S,} \mathrm{Liu} \mathrm{W,} \mathrm{Tao} \mathrm{S} \mathrm{(2006)} \mathrm{Emission} \mathrm{of} \mathrm{polycyclic} \mathrm{aromatic} \mathrm{hydrocarbons}$ in China. Environ Sci Technol 40:702-708

Yuan H, Ye S, Gao M, He X (2011) Distribution of polycyclic aromatic hydrocarbons in the surface soil of southern wetland of the Yellow River Delta and ecological risk assessment. Mar Geol Front 27:24 28, in Chinese

Zhang Y, Tao S (2009) Global atmospheric emission inventory of polycyclic aromatic hydrocarbons (PAHs) for 2004. Atmos Environ 43:812-819
Zhang Y, Tao S, Cao J, Coveney RM (2007) Emission of polycyclic aromatic hydrocarbons in China by county. Environ Sci Technol 41: 683-687

Zhang Y, Dou H, Chang B, Wei Z, Qiu W, Liu S et al (2008) Emission of polycyclic aromatic hydrocarbons from indoor straw burning and emission inventory updating in China. Ann N Y Acad Sci 1140: 218-227

Zhao J, Zhou H-d, Lu J, Wang Y-c, Hu C-h, Yuan H (2009a) Distribution and source of polycyclic aromatic hydrocarbons (PAHs) in soils of Baiyangdian area. Chin J Ecol 28:901-906, in Chinese

Zhao J, Zhou H, Lu J, Wang Y, Hu C, Yuan H (2009b) Concentration and origin of polycyclic aromatic hydrocarbons in surface soil in the Daqing River basin. Acta Sci Circumst 29:1452-1458, in Chinese

Zheng T, Ran Y, Chen L (2014) Polycyclic aromatic hydrocarbons (PAHs) in rural soils of Dongjiang River Basin: occurrence, source apportionment, and potential human health risk. J Soils Sediments 14:110-120

Zhu L, Chen Y, Zhou R (2008) Distribution of polycyclic aromatic hydrocarbons in water, sediment and soil in drinking water resource of Zhejiang Province, China. J Hazard Mater 150:308-316

Zuo Q, Tao S, Liu W (2006) PAHs in surface soils from the western watershed of Bohai Sea. Chin J Geochem 25:190-191

Zuo Q, Liu W, Tao S, Wang J, Gao Y, Tian Z (2007) PAHs in surface soils from the western watershed of Bohai Sea. Acta Sci Circumst 27: 667-671, in Chinese 